\title{
PLANNING OF MODULAR CONSTRUCTION MANUFACTURING PLANT LAYOUTS USING NON-LINEAR OPTIMIZATION
}

\author{
Chelsea Ritter* and Mohamed Al-Hussein* \\ * Faculty of Civil and Environmental Engineering, Hole School of Construction Engineering, \\ University of Alberta, Edmonton, Alberta, Canada \\ e-mails: critter1@ualberta.ca, malhussein@ualberta.ca
}

\begin{abstract}
The layout of a manufacturing facility has a significant impact on its productivity and effectiveness, as evidenced by the large amount of research surrounding the facility layout problem and optimization of the solution. In the continually evolving modular construction industry, the solution to this problem will change as often as any smaller adjustment is made to the production line. Because of this continual evolution, it is not possible to continuously change the layout, as this would quickly become prohibitive because of the cost and the need to stop production. This paper presents an optimization of the number of stations per department using the generalized reduced gradient (GRG) optimization algorithm to balance the production line. The benefit of using this algorithm is that it presents the near optimal number of stations in each department and allows for quick modifications to achieve the feasible number of stations in the ever-changing environment.
\end{abstract}

Keywords: Factory layout, Optimization, Modular construction, Production planning.

\section{INTRODUCTION}

Lean theory defines seven types of waste, which are transport, inventory, motion, waiting, overprocessing, overproduction, and defects, which should be reduced or eliminated to increase productivity in a manufacturing facility. Many, if not all, of these types of waste can be reduced through improvement of the factory layout. Because the current state of modular construction manufacturing is still often a combination of traditional stick-built construction in a factory and true manufacturing, the organization of the plant is often the result of the incremental steps that a company has taken to transform their facility, rather than an optimized and tested layout. Process improvements and technology are often key considerations for companies looking to boost their production, but improvements in the plant layout are often overlooked. Possible reasons for this include the cost and the production interruption that will occur.

Facility Layout Design (FLD) is a common research area, and can help to produce an optimized layout, which can result in improved quality in addition to the improved productivity [1]. Kundu and Dan [1] also summarize two common techniques for defining the objective function, which are adjacency based techniques and distance based techniques. Adjacency based techniques define whether or not departments are next to one another, by assigning either a 0 or 1 variable value and maximizing adjacency, while distance based techniques aim to minimize the cost of transporting materials and units between departments by minimizing a function that represents this transport cost.

Jia et al. [2] study the production line layout of a cylinder liner production line, based on either a single production line or a multi-line production line. The machines comprise the primary components of the line, and the space between them and their order are optimized by reducing the function expressed in Equation 1, where $i$ and $j$ are the machines in the production line, $s$ is the cost per unit distance of moving items between the machines, $n$ is the number of trips required to move items between the machines, and $x$ is the distance between the machines. 


$$
\min \sum_{i+1}^{m-1} \sum_{j=i+1}^{m} s_{i j} n_{i j} x_{i j}
$$

Genetic algorithms are another commonly used tool for solving facility layout problems $[1,3,4]$, and will be further analyzed in future work. The model discussed in this paper represents a straightforward way to determine the optimal department size as a first step in producing an optimized plant layout.

Ramli and Cheng [5] use analytic hierarchy process (AHP) to determine the optimal production line layout based on several other possible layouts which they had previously determined using simulation. They use various criteria to rank the effectiveness of each layout, including the space usage, utilization, return on investment, and layout output. This is a useful procedure, as it is possible to determine multiple "optimized" layouts using different simulation techniques, or even using different goals within similar models, as is presented later in the case study of this paper. AHP can allow a final, quantitative selection based on the goals of the management in the specific production facility.

While much of the literature found on this topic discusses more highly automated processes that more closely resemble true manufacturing, the application of these techniques to the modular construction manufacturing industry is possible, and will help to increase the productivity and effectiveness of the production lines.

Using an optimization algorithm will solve the problem with assumption that the current production statistics are constant. While this is useful information, the solution may involve a large investment in terms of machinery and labour hours to rearrange the factory. The necessity to halt or slow production to rearrange the plant will also have an effect on whether or not the solution to the layout problem will be implemented.

The decision of whether to implement the solution will ultimately be made by the managers at the facility. Because of this, the solution for the facility layout problem, unless the original intention was to shut down and rearrange the plant, may not be fully implemented. Rather, it may be partially implemented when the information generated is used by managers to facilitate smaller improvements that will result in smaller impacts but do not require the line to be shut down for the improvements to be implemented.

\section{METHODOLOGY}

The first step of investigating layout changes in a factory is to clearly identify the department boundaries. Departments are considered as areas where smaller components of the completed module are constructed, including the floor department, wall department, roof department, electrical department, and others. The definition of the boundaries will differ depending on the desired granularity of the layout breakdown. For example, the plant could be broken down into three departments, including a component prefabrication department, where the wall, floor, and roof components are constructed; a boxing department, where the components are attached to make a three-dimensional module; and a finishing department, where all the remaining value is added to the module. Conversely, a more detailed breakdown could also be used, separating the wall department, floor department, roof department, boxing department, electrical department, insulation department, exterior sheathing department, etc. While this may seem simplistic, it is necessary for the proper execution of the second step, which is to collect the necessary data regarding the current production statistics.

The required data to be collected for each identified department includes the station size, number of current stations, and current department production in terms of units per day per unit area. A station in this context can be defined as one area, slightly larger than the size of one component that is produced in that department, where a component has a certain value added to it. The department size will be determined based on the number of stations and the station size, since having a partial station is not useful for production. Creating a model that contains spaces not capable of accommodating full stations is unrealistic for actual implementation. The production is measured in units per day per unit area to allow for the final calculation to be based on full units. 
Next, the objective function and constraints for the model are defined. For this model, the objective is to maximize the production per day of the lowest-producing department. Constraints for this model include only allowing integer numbers of stations in each department and limiting the number of stations to non-zero values. The number of stations in each department can be represented by $n_{s, \text { department }}$; the size of each department, as measured by the floor area covered, can be denoted by $A_{s, \text { department }}$; and the production, in units per day, can be denoted by $\mathrm{P}_{\text {department, }}$, where in each variable the department subscript will indicate which department (floors, walls, roofs, boxing, insulation, electrical, sheathing) is being referred to. From here, the production statistics of the entire line can be represented mathematically. The total department size, $A_{d}$ can be calculated as expressed in Equation 2. The approximate production of the entire line, $P_{\text {total }}$, can then be calculated as the minimum production of any single department, as expressed in Equation 3. The total area required for the production line, $A_{\text {total }}$, can be calculated using Equation 4.

$$
\begin{gathered}
A_{d}=\sum\left[A_{s, \text { department }} * n_{s, \text { department }}\right] \\
P_{\text {total }}=\min \left(P_{\text {department }}\right) \\
A_{\text {total }}=\sum A_{d}
\end{gathered}
$$

Finally, the generalized reduced gradient (GRG) nonlinear solving method is used to determine the optimal solution. There are two possible objective functions that may be desired as solutions for this problem. The first, expressed in Equation 5, aims to maximize the production of the line by allocating the number of stations to each department that will most closely balance the production of the line, by maximizing the minimum department production.

$$
\begin{gathered}
\max \left(\mathrm{P}_{\text {total }}\right) \text { so that: } \\
A_{\text {total,optimized }} \geq A_{\text {total,current }} \\
n_{s}=\text { non }- \text { negative integer }
\end{gathered}
$$

The other possibility, illustrated by Equation 6, maintains continuous a constant level of production while minimizing the area used by the entire production line. This could be used for plants that are looking to add a new product line or increase their warehouse area.

$$
\begin{aligned}
& \min \left(A_{\text {total }}\right) \text { so that: } \\
& P_{\text {total,optimized }}=P_{\text {total,current }} \\
& n_{s}=\text { non }- \text { negative integer }
\end{aligned}
$$

\section{CASE STUDY}

\subsection{Plant description}

To test this model, the current plant layout and production information for industry partner, is used. The department breakdown, station size, current number of stations, and current productivity ratio is presented in Table 1. 
Table 1. Collection of current statistics for case study plant.

\begin{tabular}{crrrr}
\hline Department & $\begin{array}{c}\text { Station } \\
\text { Size } \\
\left(\mathrm{ft}^{2}\right)\end{array}$ & $\begin{array}{c}\text { Current } \\
\text { Number of } \\
\text { Stations }\end{array}$ & $\begin{array}{c}\text { Current } \\
\text { Departmen } \\
\mathrm{t}_{\text {Size }\left(\mathrm{ft}^{2}\right)}\end{array}$ & $\begin{array}{c}\text { Current } \\
\text { Production } \\
\text { (units per day) }\end{array}$ \\
\hline Floors & 1,560 & 3 & 4,680 & 2.7 \\
Walls & 720 & 4 & 2,880 & 2.1 \\
Roof & 1,560 & 1 & 1,560 & 1.8 \\
Boxing & 1,560 & 5 & 7,800 & 4.3 \\
Insulation & 1,560 & 1 & 1,560 & 2.4 \\
Electrical & 1,560 & 2 & 3,120 & 2.6 \\
Sheathing & 1,560 & 1 & 1,560 & 3.1 \\
TOTAL & & & 23,160 & 1.8 \\
\hline
\end{tabular}

Due to the lack of availability of complete information at the time of the study, only the areas of the production line up to the point where the exterior sheathing is installed are included. The plant also has two mirrored production lines, but the application of this model is applied only to production line A in this study. The department breakdown for the model at this plant includes the floor construction area, wall construction area, roof area, boxing (where the components are assembled into one module), insulation, and exterior sheathing. The current layout of the factory can be seen in Figure 1 below.

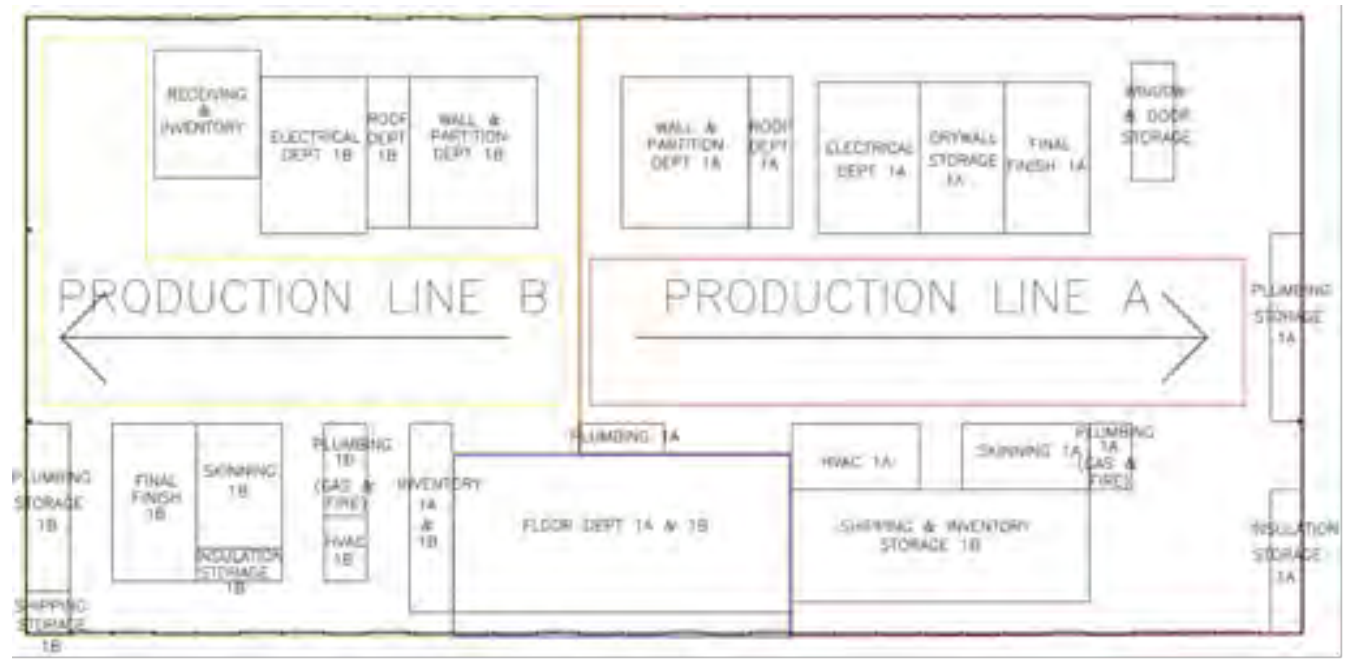

Figure 1. Current layout of case study plant.

The station sizes used include working space and tool storage space for each station, as including only the station size without this buffer would give an incorrect value for the total department size. The method of measuring the current production does not include waiting time due to upstream bottlenecks, but includes waiting time due to logistics within the department. In this way, the true capability of each station in the department is measured rather than the production due to issues outside of the department. The total production of the portion of the plant being analyzed is equal to the minimum department production, since this will set the pace for the production line. 


\subsection{Optimization model and results}

Once the initial state has been measured, the optimization model can be set up and run. To do this, as was discussed earlier, the GRG (generalized reduced gradient) nonlinear solving method in Microsoft Excel Solver is used to maximize the total production by changing the number of stations in each department, while maintaining the total area of less than or equal to the current plant area, and using only positive integer numbers of stations. The model output is presented in Table 2, and indicates that, by adjusting the number of stations in each department, and therefore changing the department sizes, the number of units produced per day could be increased from 1.8 to 2.4 (a 0.6 unit-per-day increase, or 3 additional units per week). This is the solution for the objective function stated earlier in Equation 5.

Table 2. Model to maximize production while not exceeding current floor area.

\begin{tabular}{|c|c|c|c|c|c|}
\hline Department & $\begin{array}{c}\text { Station } \\
\text { Size }\left(\mathrm{ft}^{2}\right)\end{array}$ & $\begin{array}{l}\text { Optimized } \\
\text { Number of } \\
\text { Stations }\end{array}$ & $\begin{array}{c}\text { Optimized } \\
\text { Department } \\
\text { Size }\left(\mathrm{ft}^{2}\right)\end{array}$ & $\begin{array}{c}\text { Production } \\
\text { (units/day/unit } \\
\text { area) }\end{array}$ & $\begin{array}{c}\text { Production with } \\
\text { Optimized Department } \\
\text { Size (units/day) }\end{array}$ \\
\hline Floors & 1,560 & 3 & 4,680 & 0.000576 & 2.70 \\
\hline Walls & 720 & 5 & 3,600 & 0.000729 & 2.63 \\
\hline Roof & 1,560 & 2 & 3,120 & 0.001153 & 3.60 \\
\hline Boxing & 1,560 & 3 & 4,680 & 0.000551 & 2.58 \\
\hline Insulation & 1,560 & 1 & 1,560 & 0.001538 & 2.40 \\
\hline Electrical & 1,560 & 2 & 3,120 & 0.000833 & 2.60 \\
\hline \multirow{2}{*}{$\begin{array}{c}\text { Sheathing } \\
\text { TOTAL }\end{array}$} & 1,560 & 1 & 1,560 & 0.001987 & 3.10 \\
\hline & & & 22,320 & & 2.40 \\
\hline Constraints & & $\begin{array}{c}= \\
\text { Non-negative } \\
\text { integer }\end{array}$ & $\begin{array}{c}\leq \\
23,160\end{array}$ & & maximize \\
\hline
\end{tabular}

The same model can also be used to reduce the floor area utilized by the departments, while aiming to maintain continuous production (represented by the objective function seen in Equation 6). This can be carried out by choosing to minimize the area by changing the number of departments, with the constraint that the production is equal to the current production. The output for this run of the model can be observed in Table 3, which reveals that the footprint of these departments could be reduced from 22,320 $\mathrm{ft}^{2}$ to $18,480 \mathrm{ft}^{2}$, while maintaining the same level of production.

Table 3. Model to minimize floor area while maintaining production level.

\begin{tabular}{|c|c|c|c|c|c|}
\hline Department & $\begin{array}{c}\text { Station } \\
\text { Size }\left(\mathrm{ft}^{2}\right)\end{array}$ & $\begin{array}{c}\text { Optimized } \\
\text { Number of } \\
\text { Stations }\end{array}$ & $\begin{array}{l}\text { Optimized } \\
\text { Department } \\
\text { Size }\left(\mathrm{ft}^{2}\right)\end{array}$ & $\begin{array}{c}\text { Production } \\
\text { (units/day/unit } \\
\text { area) }\end{array}$ & $\begin{array}{l}\text { Production with } \\
\text { Optimized } \\
\text { Department Size } \\
\text { (units/day) } \\
\end{array}$ \\
\hline Floors & 1,560 & 2 & 3,120 & 0.000576 & 1.80 \\
\hline Walls & 720 & 4 & 2,880 & 0.000729 & 2.10 \\
\hline Roof & 1,560 & 1 & 1,560 & 0.001153 & 1.80 \\
\hline Boxing & 1,560 & 3 & 4,680 & 0.000551 & 2.58 \\
\hline Insulation & 1,560 & 1 & 1,560 & 0.001538 & 2.40 \\
\hline Electrical & 1,560 & 2 & 3,120 & 0.000833 & 2.60 \\
\hline Sheathing & 1,560 & 1 & 1,560 & 0.001987 & 3.10 \\
\hline TOTAL & & & 18,480 & & 1.80 \\
\hline Constraints & & $\begin{array}{c}= \\
\text { Non-negative } \\
\text { integer }\end{array}$ & minimize & & $\begin{array}{c}= \\
1.80\end{array}$ \\
\hline
\end{tabular}


This model can be used in the same ways outlined above to determine the optimal department sizes for any production line footprint, or the minimal footprint required to meet any desired production. A summary of the optimized department size results for these two goals compared to the current state in the case study plant can be observed in Table 3 .

This case study indicates that the first step for layout optimization (determining department sizes) can be carried out using Excel Solver once the proper information is collected. This can also be used for determining the sizes of future state departments with process improvement and automated equipment added, so long as accurate production rates are estimated.

\section{LIMITATIONS AND FUTURE WORK}

The current scope of the model is limited to primarily the front-end of the production line. For a true representation of the optimum department sizes, the data for the remaining stations needs to be collected and all data needs to be confirmed through a reliable study. This is necessary since including the rest of the production line may reveal bottlenecks that need to be balanced, or additional space that can be used by the front-end of the production line. The inclusion of the entire line also ensures that the production reflected in the model is accurate, and will not be reduced by the stations at the end of the production line. The model can then be run to determine the size of all the departments in the production line. One limitation is that, given the current set-up of the model, departments can only be as small as one station. Factors could be introduced to the calculation to allow for partial stations to be used for some departments in order to allow work to overlap if necessary. The model also assumes that the production rate per unit area will remain constant, even once the size of a department changes. This assumption should be verified through testing and possibly simulation to ensure that it holds.

This model only optimizes the size of each department, using a simple optimization model set up in Excel. The distribution of the area on the plant floor, meaning the exact dimensions and shape of plant floor area that the department will cover, remains to be determined. This model also does not solve for the locations of the departments relative to one another. In the future, ALDEP (Automated Layout Design Program), CRAFT (Computerized Relative Allocation of Facilities Technique), or genetic algorithms are some of the options that could be combined with this model to determine a more detailed layout. This combination would allow for the size of departments to first be determined, followed by their location in the plant. Since these more advanced models will have multiple objectives, it is likely that several near optimal models will be produced. This infers that the plant managers will need to select one layout plan before proceeding. Weighting and analysis of the various layouts can be conducted using analytic hierarchy process (AHP) to quantitatively rank the layouts based on the specific goals of the manufacturing facility's management team.

\section{CONCLUSION}

This paper presents a simple optimization model that can be used as the first step toward optimizing the layout of a modular construction manufacturing production line. This model can be employed to effectively achieve several goals, including to increase the production capacity of the line without increasing its size by re-allocating the number of stations per department, or to decrease the footprint of the production line while maintaining the same productivity that is currently being achieved. It could also be used to determine the best department sizes to use in any available space, or the space required for any desired production, as long as the production rate per unit area of each department is known. Determining the optimal department sizes provides important information for plant management to use for facility improvement decisions, and is the first step in constructing a completely optimized production line layout, which will also grow to include the optimization of the locations and dimensions of each department. 


\section{REFERENCES}

[1] Kundu A, \& Dan P., "The scope of genetic algorithms in dealing with facility layout problems", South African Journal of Industrial Engineering, 21(2):39-49, 2010.

[2] Jia Z, Lu X, Wang W, Jia D., "Design and implementation of lean facility layout system of a production line", International Journal of Industrial Engineering, 20(7-8):502-514, 2013.

[3] Hu M, Wang M., "Using genetic algorithms on facilities layout problems", International Journal of Advanced Manufacturing Technology, 23:301-310, 2004. doi:10.1007/s00170-003-1637-7.

[4] Li M, Parrott L., "An improved genetic algorithm for spatial optimization of multi-objective and multi-site land use allocation", Computers, Environment and urban systems, 59:184-194, 2016.

[5] Ramli R, Cheng K., "A combined approach of simulation analysis and analytic Hierarchy process in assessing production facility layouts", Proceedings of the 21st National Symposium on Mathematical Sciences (SKSM21) (pp. 1092-1097), 2014. AIP Publishing LLC. doi:10.1063/1.4887743. 